\title{
La sátira en los Cuentos chinos de Abraham Valdelomar
}

\author{
Ricardo Silva-Santisteban Ubilluz \\ Academia Peruana de la Lengua \\ Pontificia Universidad Católica del Perú \\ rsilva@pucp.edu.pe
}

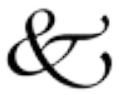

Abraham Valdelomar nació en Ica en 1888 y falleció trágicamente en Ayacucho en 1919, luego de una corta pero deslumbrante carrera literaria en la que acometió todos los géneros literarios. En Valdelomar se ha privilegiado al admirable cuentista que fue con detrimento del poeta, el ensayista y el dramaturgo en una obra vasta y desigual en que se destacan dos tonos nítidamente diferenciados: uno exotista y artificial y otro en que se respira y palpa el ambiente de su aldea natal. Se trata, pues, de dos facetas del mismo escritor que coexistieron a lo largo de su vida: la esteticista, que podemos asimilar al modernismo, y la moderna que podemos asimilar a la posmodernista. También pueden encontrarse en él otras uniones de contrarios como la trágica y la satírica, la dramática y la irónica, la madura y la pueril, la cándida y la engolada. De ahí que pueda advertirse que, una vez madurada su expresión, no continúa en Valdelomar, por ejemplo, la evolución formal de su escritura, sino que los aspectos esteticista y moderno se dan al mismo tiempo. Por supuesto que esto a veces no puede observarse en forma muy clara, pero después de la creación de los cuentos criollos, es decir de "El Caballero Carmelo", "Los ojos de Judas" y "El vuelo de los cóndores", tenemos la composición de algunos de los cuentos incaicos de Los hijos del Sol, de índole nítidamente esteticista, y la de los cuentos chinos, de carácter satírico pero también con trozos de prosa decadentista.

Gran parte de lo que escribió se desliza hacia la narración ya sea que se trate de artículos, ensayos o estudios históricos. Valdelomar es lo que se llama un narrador nato y, en mi concepto, no solo es el verdadero creador del cuento peruano y el más destacado de los escritores pos-modernistas peruanos, sino también uno de los más grandes cuentistas peruanos (si no el más grande e importante) sobre todo por el aire de originalidad que se respira en sus cuentos, su variedad, su habilidad para la conducción de los eventos narrativos y por la excelencia de su estilo. 
Gracias a Guillermo Billinghurst, en cuya campaña electoral por la presidencia de la república había participado activamente, Valdelomar fue nombrado durante su gobierno director del diario oficial El Peruano y luego, más importante para la vida del escritor y de acuerdo a sus anhelos, Secretario de Segunda Clase de la Legación de la República del Perú en Italia. Valdelomar dejó el puerto del Callao el 1 o de julio de 1913 con dirección a Italia. Pasaría, entre otras ciudades, por Nueva York y París para arribar a Roma a comienzos del mes de agosto.

Puede considerarse feliz desde el punto de vista de creatividad literaria el viaje a Europa de Valdelomar. Los viajes por barco dejan mucho tiempo libre y el paisaje, con sabor a infinito, espacialmente hablando, sirve para catalizar experiencias. Conjeturo que algunos cuentos de Valdelomar fueron escritos o planeados en este viaje. Por ejemplo, “Tres senas, dos ases”, uno de los Cuentos yanquis, se encuentra fechado en Nueva York. Otros, con seguridad, fueron corregidos y reescritos durante el viaje. "Los ojos de Judas", uno de los mejores, se sabe, por una de sus cartas, que ya estaba terminado antes del viaje. "El Caballero Carmelo", su cuento más famoso, fue escrito en Roma en el segundo semestre de 1913.

El conocimiento directo del arte italiano y europeo tuvo un impacto beneficioso para un intelectual aspirante y de sensibilidad como Valdelomar que fue además un interesante dibujante. Debe confesarse que para todo sudamericano apreciar en vivo y en directo la herencia del arte occidental es una experiencia invalorable además de inolvidable. Parte de esta experiencia vital de Valdelomar se encuentra expresada en sus Crónicas de Roma que tocan temas diversos. Por sus cartas se aprecia también el inicio de sus estudios universitarios en Roma y sus prácticas de esgrima.

Pero el 4 de febrero de 1914 se produce en el Perú el golpe militar del coronel Óscar R. Benavides contra el gobierno del presidente Guillermo Billinghurst. Así, todos los sueños literarios y artísticos de Valdelomar se fueron al traste gracias a este golpe. Valdelomar renuncia a su cargo el 6 de febrero, apenas recibida la noticia en Roma, lo cual habla bien de su comportamiento. La renuncia del escritor, que seguía principios de lealtad y de ética elementales, motiva su momentánea ruina personal y de algunos familiares suyos que trabajaban para el gobierno. Sin embargo, él es el más perjudicado ya que significaba la terminación abrupta de su enriquecedora estadía en Italia y la cercanía a otros países europeos como Francia y España. Como bien le indica a un primo suyo:

Ya sabrás mi ruina momentánea y la de mi familia. Sin embargo, nada es capaz de arredrarme y lo que me hace sufrir hasta el martirio es no estar hoy muerto por defender a mi Gobierno o expatriado a su lado (2000:151). 
A su madre le escribe comunicándole que piensa ir quizá a Buenos Aires ya que no puede permanecer más en Roma:

Como comprenderás lo primero que hice fue renunciar irrevocablemente a mi puesto pues no cometeré la ignominia de servir al lado del que ha traicionado a mi amigo (2000:154).

Probablemente después de epopeyas interiores acerca de su destino, la dura realidad le hace ver al escritor los hechos con lucidez. Valdelomar pasa por París en el mes de marzo pero en abril ya se encuentra nuevamente en el Perú.

En el mes de junio es detenido por la policía. En un reportaje en broma que escribió su amigo el poeta Enrique Bustamante y Ballivián, Valdelomar comenta:

Me creyeron un conspirador terrible; el brazo derecho de don Roberto; el más decidido enemigo del régimen, el más implacable y peligroso de los conjurados...

-iA ti?

-A mí que sabes que, por ahora, no conspiro sino contra la inviolabilidad de la gramática...

-Pero, ¿qué hacías en casa de Durand?

-Nada. No hacía nada. Pasaba por allí, vi el barullo policial, soy amigo de la familia y entré, para salir al poco rato en compañía de dos sujetos mal encarados y peor vestidos que no sabían de seguro de las higiénicas propiedades del jabón hacía por lo menos dos años.

-iQué horror!

-iQué olor!, dirás.

-Sigue, sigue...

-Verás: Yo tenía en la mano un rollo de cuartillas, un cuento, el mismo que aparece en este número de La Opinión "El vuelo de los cóndores". Verle un comisario y echarse sobre él fue todo uno. Tan rápido y tan certero fue el golpe policial que no pudo escapar, a pesar de sus alas, ni uno solo de mis cóndores... En casa de Durand y con papeles, iclaro!, lo menos tenía yo que ser un macabro conductor de correspondencia revolucionaria... Y, sin más explicaciones, a la Intendencia.

Quizá sea el humor, dentro del género cómico, el que más abunda en la creación literaria de Valdelomar, como puede apreciarse en este corto fragmento. Valdelomar es autor de irónicos ensayos como los dedicados a varios animales (el cerdo, el gallinazo, las tortugas), de crónicas, de ingeniosas entrevistas y de una notable prosa miscelánea desperdigada en publicaciones periódicas (Diálogos máximos, Fuegos fatuos, Decoraciones de ánfora, etc.). Pero la faceta del humor es la que más aflora sobre todo después de su obligado retorno a Lima 
Reintegrado a la vida limeña, Valdelomar comienza un período de asombrosa fertilidad como prosista. Trabajó como un esforzado periodista creativo con colaboraciones de todo tipo: artículos, comentarios, poemas, cuentos, ensayos, etc. Desde 1915 hasta 1917 sus colaboraciones, sobre todo en el diario La Prensa, son impresionantes por su volumen y calidad.

A fines de junio de 1915 se recibió en Lima la noticia de la muerte del presidente Billinghurst, desterrado en Chile, lo que motivó un sentido artículo necrológico de Valdelomar en el que se puede ver cuánto lo apreciaba y cómo lo consideraba una figura ejemplar. Según Valdelomar, su gobierno tenía:

que luchar con males inveterados; no sabe intrigar; no tiene flexibilidades palatinas; la práctica del bien y su sinceridad, han dejado en su alma ingenuidades; no puede distinguir entre los que lo rodean, al cortesano servil, adulador y malévolo y al ciudadano entusiasta y honesto; ignora cómo se miente; la farsa le repugna; es escrupuloso en el manejo de los caudales públicos; se interesa en los grandes asuntos nacionales y olvida las pequeñas urdimbres de la política; el cóndor no se da cuenta de lo que pasa a ras de tierra $(2001$, III, 88$)$.

Un político así no podía sobrevivir, tenía que caer y luego ser calumniado. Se lo difamó, cuando se encontraba desterrado en Chile, afirmándose que intrigaba desde allí una invasión al Perú en un momento de malas relaciones con el país vecino. Valdelomar comenta este hecho:

Y esta vida útil, este corazón fuerte, agobiado por el peso de la injusticia, este precioso espíritu, es cortado por la afilada hoja de una vulgar calumnia. Se tocó lo único que no se podía tocar, se buscó el más sutil veneno, se habló de su patriotismo y se consiguió amargar sus últimos instantes (2001, III: 88).

Al poco tiempo de la muerte de Billinghurst se produjo un cambio de gobierno al ser elegido don José Pardo, que asumió el poder a mediados de agosto. Valdelomar comenzaría a trabajar entonces como secretario del primer ministro del nuevo gobierno don Enrique de la Riva-Agüero Riglos.

La publicación de los Cuentos chinos se realizó en forma continua el 3, 11 y 16 de octubre y el 10 de noviembre de 1915 en La Prensa, seguida de uno más en el mes de febrero del año siguiente en la revista Rigoletto que dirigía Leonidas Yerovi. Al momento de recopilar y seleccionar sus cuentos en el libro El Caballero Carmelo de 1918, Valdelomar recogió la totalidad de la serie, prefiriéndolos a otros cuentos más valiosos ya escritos y aparecidos en publicaciones periódicas.

Todos los críticos que han comentado los Cuentos chinos de Valdelomar, les dan a estos poca importancia dentro de su narrativa. Efectivamente, dentro del conjunto de las narraciones de Valdelomar, languidecen como cuentos. Hasta 
podemos cuestionar seriamente si son efectivamente cuentos ya que Valdelomar no hace otra cosa sino relatar en clave china los sucesos de la deposición de Billinghurst, resumir fases de la historia del Perú o criticar acremente a personas o instituciones.

El propio Valdelomar parece haber advertido la debilidad que poseían como piezas aisladas. Conjeturo que ese es el motivo por el que ofrece el conjunto como una unidad al publicarla completa en la edición de sus cuentos de 1918. Con el conocimiento de qué instituciones o personas se trata, los Cuentos chinos se revisten del interés, del aura que les ofrece su contenido de doble fondo

La frase "cuento chino" posee, al menos en el Perú, la significación de una historia engañosa, que no puede creerse por ser una tomadura de pelo. En el caso de Valdelomar, este parece sugerir, con la denominación de "chino", que se trata de una historia engañosa porque, precisamente, no es un cuento chino sino peruano; sin embargo, es chino porque se encuentra ubicado geográficamente en China y con personajes de nombres, aparentemente, chinos.

Cuando Valdelomar acomete la escritura de los Cuentos chinos, tenía ya la experiencia vertida en los Cuentos yanquis en los que presenta a los yanquis como adoradores del dinero. El cosmopolitismo de época lleva a Valdelomar a la creación de estos cuentos en los que intenta crear la realidad de una sociedad deformada por la codicia, cuya única aspiración es la del dinero, ante cuyo altar puede entregarse hasta la propia vida. Con fino humor, en estos cuentos, Valdelomar iguala el triunfo con la posesión del dinero, cuya consecusión es el fin último y definitivo del yanqui. Sin embargo, en los Cuentos yanquis Valdelomar no intenta satirizar sino ironizar y contemplar con humor sus personajesmarionetas que se enfrentan ante la propia muerte o son capaces de traicionar a un amigo por el anhelado y divino dinero.

Conjeturo que la escritura de los Cuentos chinos es más bien lo que podríamos denominar la historia de una venganza. Como comentaba hace unos momentos, la muerte del Presidente Billinghurst fue un duro golpe para Valdelomar. No es extraño que ante una serie de sentimientos de lealtad hacia su antiguo jefe, Valdelomar "del más humilde de sus leales" como se consideraba a sí mismo en la dedicatoria manuscrita del ejemplar de su libro La Mariscala que poseo, haya querido narrar los sucesos de la deposición de Billinghurst como presidente de la República a la vez que denigrar e insultar al golpista.

Se sabe que la sátira es una venganza contra aquello que le disgusta a un determinado ser humano. Se trata, pues, de la demostración de una hostilidad contra ciertos aspectos del abuso o de la estupidez humanos. Por otro lado, la sátira es la forma más utilizada en la literatura política. Como la sátira apunta a determinados sucesos conlleva muchas veces una limitación inherente a los mismos. 
Como bien dice Matthew Hodgart "contemplar el mundo con una mezcla de risa e indignación no es el más noble ni el que produce mayor número de obras de arte excelsas" (1969:10). Es verdad, pero la sátira tiene su lugar bien ganado en las distintas tradiciones del mundo y grandes poetas la han ejercido: Arquíloco, Semónides, Catulo, Horacio, Villon, Quevedo, etc. El gran tema de la sátira, por lo general, es la burla y el escarnio de la pequeñez, la ridiculez de ese pequeño e inflado ser llamado hombre.

Los llamados Cuentos chinos, quizá el conjunto más endeble de la narrativa de Valdelomar, fueron escritos con una finalidad política inmediata: crear en la exótica y lejana China un espacio geográfico y una sociedad en la cual poder reflejar, encubierto a ratos con un lenguaje poético, los sucesos del momento en el Perú, ya sea de instituciones o personajes como los ministros y el dictador de turno que había dado un golpe de Estado. El tono de los cuentos chinos es satírico y, en ellos, como en las novelas orientales de Voltaire, que enmascaran personajes y sucesos de la sociedad francesa de su tiempo, Valdelomar narra la caída de Billinghurst y arremete contra los actores que la provocaron.

Estimo los Cuentos chinos más como sátira pura que como verdaderos cuentos. A pesar de los trozos de prosa poética decadente con que se adornan ciertos momentos de los mismos así como los párrafos finales de los cuentos. Veamos uno de ellos, compuesto de una sola frase:

-dijo el ermitaño-, e induciendo a Chin-Fú, emprendió el camino por los matorrales solitarios, hacia el centro de la despoblada plaza de la gran aldea, mientras la luna filtraba sus rayos violados por entre las ramas de los sicomoros y ponía en la tierra, sobre las hojas secas y quebradizas, la fantasía nítida de una blancura rota, tal como sobre el mar juega de vez en cuando la espuma de las olas que se debaten contra las costas rocallosas, y que, cambiando, inestables, leves y frágiles, desaparecen inexorablemente en el misterio de la noche... (1918:177).

Valdelomar, en los Cuentos chinos, no quería narrar, su intento era burlarse e insultar. Como cuentos son más bien esquemáticos. Sin embargo, creo que Valdelomar, escritor irónico y con momentos de gran humor, pasó por el tamiz de una crítica implacable en los Cuentos chinos a personajes, a instituciones y a todo un sistema corrupto y lleno de vicios.

Quizá tendríamos que remontarnos, para encontrar ejemplos similares entre otros escritores peruanos, a la crítica muchas veces acerba y disolvente de Manuel González Prada. En el caso de Valdelomar, que utiliza como vehículo la narración, la sátira, por ratos, deriva a la ironía y al humor. Pero la crítica social, no por ello, es menos vigorosa.

En el estudio de Willy Pinto Gamboa, La sátira en Valdelomar y en Yerovi (1973:31), se encuentran desentrañadas las alusiones geográficas, de perso- 
najes, de instituciones y de partidos políticos contenidas en estos cuentos, a partir de informaciones proporcionadas por el doctor Luis Alberto Sánchez. Esta información (que se encuentra citada en el segundo tomo de las Obras completas, p. 17), ha sido muy bien resumida por Manuel Miguel de Priego en su biografía de Abraham Valdelomar:

El escenario en que se mueven los personajes de las fábulas es Siké (el
Perú) y específicamente la Gran aldea de Siké (Lima), el Palacio (sede de
gobierno), el Castillo (el cuartel de Santa Catalina), el local del Congreso
(habitado por el Gran Consejo de Siké, también llamado el Hediondo pozo
siniestro o Chun-Gau-Loó).

Los personajes protagónicos son Chin-Kau (el Presidente Billinghurst), Ton Say (el general Enrique Varela) y Rat-Hon (el coronel Óscar R. Benavides); luego Tu-Pay-Chong (Fernando Gazzani), Si-Tay-Chong (Hildebrando Fuentes), Si-Tu-Pon (general Pedro E. Muñiz), y son también aludidos SiMo-Hon (Bolívar) y Kon-Sin-Sak (don Nicolás de Piérola).

Hacen comparsa los Chan-Laá (políticos) grupo en el que se infiltran los Chin-Fu-Ton (arribistas serviles y soplones), los bati-ku (civilistas), los chicané (leguiístas), los Sac-Chay (gobernadores) y "un tercer partido encabezado por disidentes del de la barba de nieve" es decir, del ya mencionado Kon-Sin-Sak. Los españoles son aludidos como los manchúes (2001: 235).

Como puede apreciarse por una simple lectura, los nombres chinos forjados por Valdelomar son completamente fantásticos. Unas veces cumplen funciones de sarcasmo. Por ejemplo al coronel Benavides, autor material del golpe de estado, se le da el apelativo de Rat-Hon. En otros casos sirven como identificación. En el caso del Perú, como se sabe, existen dos grandes libertadores extranjeros: José de San Martín, argentino, y Simón Bolívar, venezolano. Valdelomar se refiere al segundo como Si-Mo-Hon. Se trata, pues, de trasparentes referencias en clave de personajes, instituciones, grupos, ciudades, partidos políticos, etc. Otras, lo son menos y por eso la cita del autorizado comentario de Manuel Miguel de Priego.

Valdelomar parece haber tenido desde el inicio de la escritura de los Cuentos chinos, el componer una serie. Cerca del final del primero de ellos, "Las vísceras del superior", indica con claridad que la conducta de los lugartenientes de RatHon "serán motivo de otro capítulo". Quien se encarga de narrar los cuentos es "Ta-Ku-Say-Long Exdirector de la Biblioteca Nacional de Tokio, condecorado con el dragón rojo, oficial del Crisantemo Azul, etc.”, según se indica al final de los cuentos en las publicaciones periódicas. Puede apreciarse, la inconsistencia respecto de la biblioteca de la capital japonesa, no china. Ta-Ku-Say-Long un alter ego oriental de Valdelomar. 
En el primero de los cuentos, "Las vísceras del superior", Ta-Ku-Say-Long tiene como escucha a su sobrino a quien le narra cómo Chin-Kau fue elegido para gobernar Siké:

Ante la amenaza de una disolución y de que el fuego del cielo arrasara la aldea, y aniquilara a sus habitantes, acordaron un día dar tregua a sus pasiones y elegir, de común acuerdo un mandarín que fuese aceptado por todos. El designado fue Chin-Kau. Una tarde, cuando empezaban a caer las hojas de los ciruelos y el arroz florecía, el Gran Consejo entregó el gobierno a Chin-Kau, quien, por haber vivido muchos años lejos de su pueblo, por su reconocida honradez, por su notable competencia, por su espíritu generoso y benévolo era la esperanza de Siké. Cuando el Gran Consejo le ungió, todo el país aplaudió el ungimiento. Los altos dignatarios, las más discretas damas, la sana juventud, los sacerdotes de Budha, y hasta los más humildes laboreros dejaron aquel día sus arrozales y se dirigieron al palacio de Chin-Kau a darle el saludo. Desde el más alto y gordo juez hasta el más sabio sacerdote y el más infeliz y flaco chino de Siké, concurrieron a la fiesta; se quemó innumerable cantidad de cohetecillos, se representó en el teatro grandes dramas legendarios y el espíritu nacional vibró en Siké. Con extraordinaria fuerza se alababa la prudencia, la sabiduría, la honradez, la generosidad y hasta la belleza física de Chin-Kau, que era feo, porque los habitantes de Siké parecían hijos directos de Chin-Chun, el dios del Servilismo (1918: 157).

Pero al poco tiempo de su elección comienzan de nuevo las pugnas, las intrigas y, finalmente, la conspiración. Enterado de ello Chin-Kau, es decir el presidente Billinghurst, manda llamar a Ton-Say (junco flexible), es decir el general Enrique Varela, sobre la conspiración de Rat-Hon, es decir el coronel Óscar R. Benavides. Ton-Say llama a Rat-Hon para aclarar el asunto:

Rat-Hon oyó en silencio; entristecióse y dos lágrimas cayeron de sus ojos desviados. Tembloroso, solo pudo contestar, entrecortadamente.

-Por los arrozales sagrados de Kay-Pen; por las sabias máximas de Confucio; por los crepúsculos rosados de Haytay; por todos los cereceros en flor de los siete cielos; por los colmillos del elefante gordo de Budha, ¿cómo puedes concebir gran general y padre y jefe mío, que yo pueda conspirar contra la estabilidad del magnánimo sabio Chin-Kau a quien acabo de pedir puestos para los míos? Tu reproche entristece mi alma como la caída del sol entristece el mundo... iAy! iYo me muero de pena!

Ton-Say se conmovió con la respuesta de Rat-Hon. Otras dos lágrimas igualmente gordas cayeron sobre los pómulos de Ton-Say y solo pudo agregar:

-iTe envidian, Rat-Hon; y por eso te calumnian!...

- Puedes dormir tranquilo -dijo, retirándose, conmovido, Rat-Hon. 
Ton Say se dirigió donde el gran mandarín Chin-Kau y le repitió la frase de Rat-Hon, agregando:

-iPodemos dormir tranquilos, Gran Señor! (1918: 159-160).

Pero ya se sabe que, precisamente entre los militares, el honor es una virtud muy relativa y esa misma noche se produce la revuelta del vituperable Rat-Hon:

Chin Kau durmió aquella noche en el palacio de Siké y Ton-Say en el Castillo, rodeado de su ejército. Pero he aquí que cuando cayó la noche sobre la ciudad y cuando las tinieblas eran tan negras como el alma de Rat-Hon, unas sombras se dirigieron hacia el dormitorio del General Ton-Say, convirtiéndolo en una verdadera papilla. Después, otras legiones capitaneadas directamente por Rat-Hon se dirigieron al palacio, atacaron a Chin-Kau, lo deportaron y lo asesinaron a disgustos. El autor de todo este proceso vituperable fue declarado mandarín y Rat-Hon subió al poder por el servilismo, la cobardía y la confabulación pecaminosa de los habitantes de Siké (1918: 160-161).

Si el primero de los Cuentos chinos se centra en la innoble y desleal conducta de Rat-Hon, en el segundo, "El hediondo pozo siniestro", se narra la conquista del Tahuantinsuyo por los españoles, la emancipación lograda finalmente por Simón Bolívar y la humillación a la que somete al Perú este libertador por la carencia de patriotismo del Congreso -es decir, el hediondo pozo siniestropara luego tratar nuevamente de Rat-Hon y de algunos de sus lugartenientes. El personaje principal atacado es el primer ministro Si-Tay-Chong, es decir, Hildebrando Fuentes:

... y sobre todo el inolvidable, el inolvidabilísimo Si-Tay-Chong, "el desvergonzado", que era más sucio y asqueroso que un escupitajo de suegra desdentada en cara de borracho tuberculoso. Si-Tay-Chong era plebeyo, astroso, mala persona, bajo de alma y de cuerpo, de espíritu mefítico, de uñas largas y negras, pediguieño en su mocedad, insolente en su apogeo; adulador a los señores, déspota de los infelices, megalómano, cínico, inmoral, bruto, sucio, servil, falso, artero, intrigante, malévolo, presuntuoso, vacuo, fatuo, desleal, sin ley, sin conciencia, sin dios, algo buen mozo y de ojos dormidos, creía poseer el secreto de las siete ciencias, la trascendental filosofía de Buda, las sabias máximas de Li-Kay-Pé, el noble uso de las armas, la difícil ciencia de la administración y la brillante virtud de la oratoria. Hablaba de honradez inmaculada y cobijaba malhechores; enseñaba en la Academia de Siké y engañaba en ella, con falsas doctrinas, a la candorosa juventud; era capaz de vender su alma por un mimpau; su cuerpo por un nido de golondrinas; su honor por una torta de sesos de murciélago; era un chino infecto; no había por dónde cogerlo. Todo esto es pálido retrato de lo que era en verdad, SiTay-Chong, "el desvergonzado".

Y así llegó a ser ministro de Siké en el gobierno desgraciado del famoso 
mandarín Rat-Hon. Por todo esto se verá que los habitantes de Siké merecían la suerte que les estaba deparada por Buda, el admirable padre de la sabiduría, el dispensador de beneficios, el que hace florecer los crisantemos en la primavera, y rompe el broche verde por donde surgen en los lagos tranquilos, las blancas flores del loto frágil, bajo el cielo hondo y azul, en los paisajes multicolores de las comarcas chinas... (1918: 168-169).

Puede observarse, por la lectura del último párrafo, que este tiene la función de endulzar en algo la página de oprobios que la precede. Como bien dice Manuel Miguel de Priego:

Probablemente jamás nunca antes ni después en el Perú y en el mundo encontraremos en las páginas de la literatura una acumulación tan grande de adjetivos y frases agravantes como ésta de Ta-Ku-Say-Long contra el carcelero Si-Tay-Chong ( 2001:240).

No extraña, pues, que Valdelomar incluyera la serie completa de los Cuentos chinos, a pesar de sus debilidades narrativas, en su selección de El Caballero Carmelo de 1918. Quizá todavía no podía él mismo apreciar la calidad de la serie con relación a la de sus otros cuentos. Quizá también se tratara de un último homenaje a don Guillermo Billinghurst, no solo su antiguo jefe sino también uno de los amigos a quien estaba dedicado El Caballero Carmelo. De cualquier forma, se había vengado de Rat-Hon y de sus lugartenientes y pudo poner así el dedo en la llaga de instituciones y personajes que merecían el justo castigo de su pluma.

\section{Referencias bibliográficas}

HODGART, Matthew (1969) La sátira. Madrid: Ediciones Guadarrama.

MIGUEL DE PRIEGO, Manuel (2001) El conde plebeyo. Lima: Fondo Editorial del Congreso.

PINTO GAMBOA, Willy (1973) La sátira en Valdelomar y en Yerovi. Tesis de Doctor. Lima: Universidad Nacional Mayor de San Marcos.

SILVA SANTISTEBAN, Ricardo (editor) (2000) Valdelomar por él mismo. Lima: Fondo Editorial del Congreso del Perú.

VALDELOMAR, Abraham (1918) El Caballero Carmelo. Ciudad de los Reyes del Perú. Lima: Talleres de la Penitenciaría de Lima.

VALDELOMAR, Abraham (2001) Obras completas. Cinco tomos. Lima: Ediciones Copé. 